\title{
Digital Storytelling and Educational Benefits: Evidences from a Large-Scale Project
}

\author{
Nicoletta Di Blas and Paolo Paolini \\ Department of Electronics and Information, Politecnico di Milano, \\ Piazza Leonardo da Vinci 32, 20133, Milano, Italy \\ \{nicoletta.diblas, paolo.paolini\}@polimi.it
}

\begin{abstract}
In this paper we investigate the potential of digital storytelling in the context of formal education (i.e. as a classroom activity). Our discussion is based upon the empirical evidence provided by a six-years' experience in Italian classes of all school grades (including pre-school), which has involved so far more than 17,000 students. The evaluation data come from surveys, direct interviews and focus groups with hundreds of teachers. Digital storytelling seems to provide substantial benefits of various kinds, ranging from knowledge acquisition, to media literacy and improved attitudes and behaviors. Nearly 700 narratives, created so far, can be accessed at www.policulturaportal.it.
\end{abstract}

Keywords: eLearning, Digital Storytelling, Authoring-Delivery Environment, Computer Supported Collaborative Learning.

\section{Introduction}

This paper is about digital storytelling in formal education. The issue we would like to address is if digital storytelling at school can provide educational benefits, what kind of benefits and under which conditions. The paper is based upon the data collected in PoliCultura (www.policultura.it), an initiative by HOC-LAB of Politecnico di Milano (Italy) that invites students, of all school grades, to create their own multimedia "narratives". PoliCultura has involved more than 17,000 Italian students from school year 2006 to June 2011. They will become more than 20,000 by June 2012. The extensive monitoring of the impact has included online surveys, skype interviews, focus groups with the teachers as well as the analysis of the students' artifacts performed each year by a panel of experts. The digital storytelling activity turns out to be like a pebble thrown in a pond: it promotes not only curricular benefits (e.g. like increased knowledge of a subject matter), but also non typical benefits, like the development of a professional attitude and improved relationships within the class.

A few distinctive features of our approach to digital storytelling must be clarified before digging into details:

A. In order to let participants free to integrate the activity into the curriculum, we take the concept of narrative in a very broad sense, which includes but is not limited to fiction. Authors can (and actually do) mix different literary genres at their will and they can narrate stories about virtually any subject. 
B. Multimedia narratives are a collaboration of the entire class, not the result of individual efforts $[8 ; 12]$. There are two reasons for this: first, we want to promote team building and group work within the class as educational benefits: individual talents are encouraged to serve a common end. Secondly, it is known from literature $[18 ; 21]$ that a team effort provides great opportunities for inclusion of underperforming and marginalized students and again, inclusion is one of the benefits we wish to promote.

C. The narrative creation is embedded into a larger framework of standard curricular activities; it is not a discrete enterprise. No teacher would devote 2-3 months to creating a multimedia narrative if it was totally unrelated to the curriculum; even if they wanted to, it would not be possible, since curricula (in Italy and in most countries), are quite prescriptive.

D. All the narratives, even if they embed fiction, may be defined as "serious", in the sense that they are linked to some school activity (a research, a project, a subject...) and are aimed at educational benefits.

E. Teachers can play various roles: facilitator, supervisor, co-author, "director", trainer, producer, etc. A PoliCultura narrative is obviously a product by the students and the teacher, but the involvement degrees vary a lot. Some teachers orchestrate the whole work, others take care of content only, leaving students to play, at their will, with technology; others let the students organize themselves, etc. There is an obvious general pattern: younger students (from 5 to 8 years of age) require more intervention than older students.

This paper is organized as follows: in section 2 we describe the PoliCultura initiative, providing also brief examples of narratives. In section 3 we present the evaluation data and we discuss their interpretation. In section 4 we present some related works. In section 5 eventually we draw conclusions and present our future directions.

\section{The Experimental Context}

PoliCultura is an initiative by HOC-LAB of Politecnico di Milano, started in school year 2006. HOC-LAB had developed at that time an authoring tool ("1001stories") for quick and easy production of multimedia applications that was then used (and still is) by the lab's staff for applications in the fields of eCulture, eTourism, corporate communication and so on $[11 ; 26]$.

Some of the tool's features led us to think that it might work well in school environment too: it was very easy to use and it could support group work quite well. Eventually, the final narrative could be delivered over multiple channels and devices, which are beloved by youngsters: Web for PC, iPad, iPhone, tablet PCs, podcast... Thus in 2006, we launched a national competition on digital storytelling based on our tool (which was offered as a free web service). High schools only were involved. Following a number of requests, all school grades were included over the years. On the whole, more than 17,000 students and 700 teachers have taken part in PoliCultura so far, with a high number of registrations for the current year (Table 1). 
Table 1. PoliCultura: participation from 2006 up to 2012 (the latter being a forecast)

\begin{tabular}{|l|c|c|c|c|c|c|c|}
\hline & $2006-07$ & $2007-08$ & $2008-09$ & $2009-10$ & $2010-11$ & $2011-12$ & TOT \\
\hline Pre-School & - & - & 25 & 10 & 13 & 10 & $\mathbf{5 8}$ \\
\hline Primary s. & - & 55 & 69 & 52 & 60 & 50 & $\mathbf{2 8 6}$ \\
\hline Junior H.S. & - & 36 & 57 & 36 & 44 & 50 & $\mathbf{2 2 3}$ \\
\hline High School & 57 & 38 & 40 & 45 & 56 & 50 & $\mathbf{2 8 6}$ \\
\hline & & & & & & & \\
\hline Narratives & $\mathbf{5 7}$ & $\mathbf{1 2 9}$ & $\mathbf{1 9 1}$ & $\mathbf{1 4 3}$ & $\mathbf{1 7 3}$ & $\mathbf{1 6 0}$ & $\mathbf{8 5 3}$ \\
\hline Students & $\mathbf{1 , 4 2 5}$ & $\mathbf{3 , 2 2 5}$ & $\mathbf{4 , 7 7 5}$ & $\mathbf{3 , 5 7 5}$ & $\mathbf{4 , 3 2 5}$ & $\mathbf{4 , 0 0 0}$ & $\mathbf{2 1 , 3 2 5}$ \\
\hline
\end{tabular}

Schools are notified of the initiative by the regional branches of the Italian Ministry for Education. Typically, two or more teachers from the same school decide to participate together. HOC-LAB provides participants with a short guide on how to make a multimedia narrative: the guide is 12 pages long and it addresses both communication and technological issues (how to use the 1001stories toolkit, how to record MP3 files). The technological requirements for using the authoring environment are light and in addition no specialized technological skills are required. So almost any teacher from any kind of school can take part: pedagogical knowledge is much more necessary than technical knowledge to successfully complete the experience $[13 ; 24]$. When the work is completed, participants can decide whether to take part in the national competition or not. A jury selects the finalists, who are invited to the LAB's premises in Milan, in June, for the celebration day. Workshops (for the students) and focus groups (for the teachers) are organized, in order to allow the LAB's researchers investigating the impact of the toolkit with its direct users.

\subsection{The Authoring Environment: 1001stories}

1001stories is the authoring environment with which schools create the narratives; it is made available as a free web service. It consists of three main components: a Content Management System, a Preview Engine and a Generator (that can be used by staff people only). The CMS is needed in order to clearly separate the authoring phase, performed via a web service, from the actual delivery of the narrative through multiple channels (Figg.1 and 2).

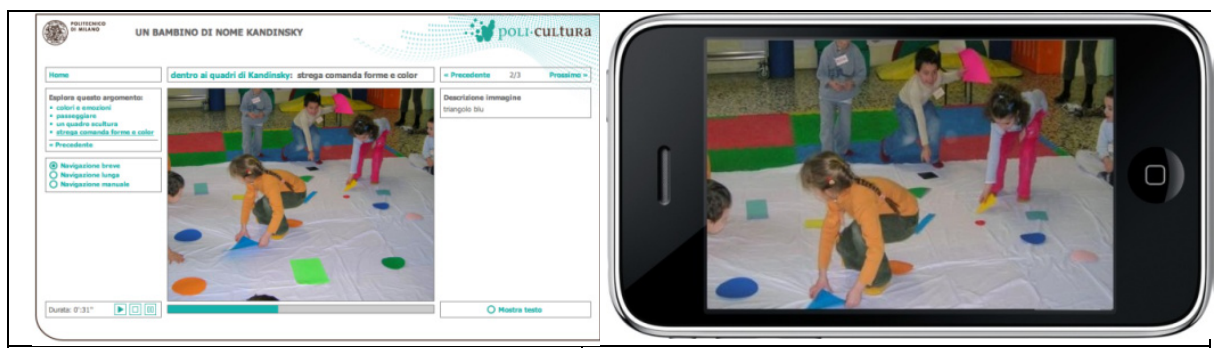

Fig. 1. and 2. Web for PC version (left) and mobile version (right, on iPhone) of a multimedia narrative by pre-school children 
The CMS supports a number of functions: creation and editing of the narrative's structure, data entry of text, images, audio and preview of the narrative. The authoring interface (Fig. 3) is quite easy to manage: the average learning time in a primary school is 20 minutes. The Preview engine allows playing the content at any stage of the work, thus providing an immediate reward to the authors.

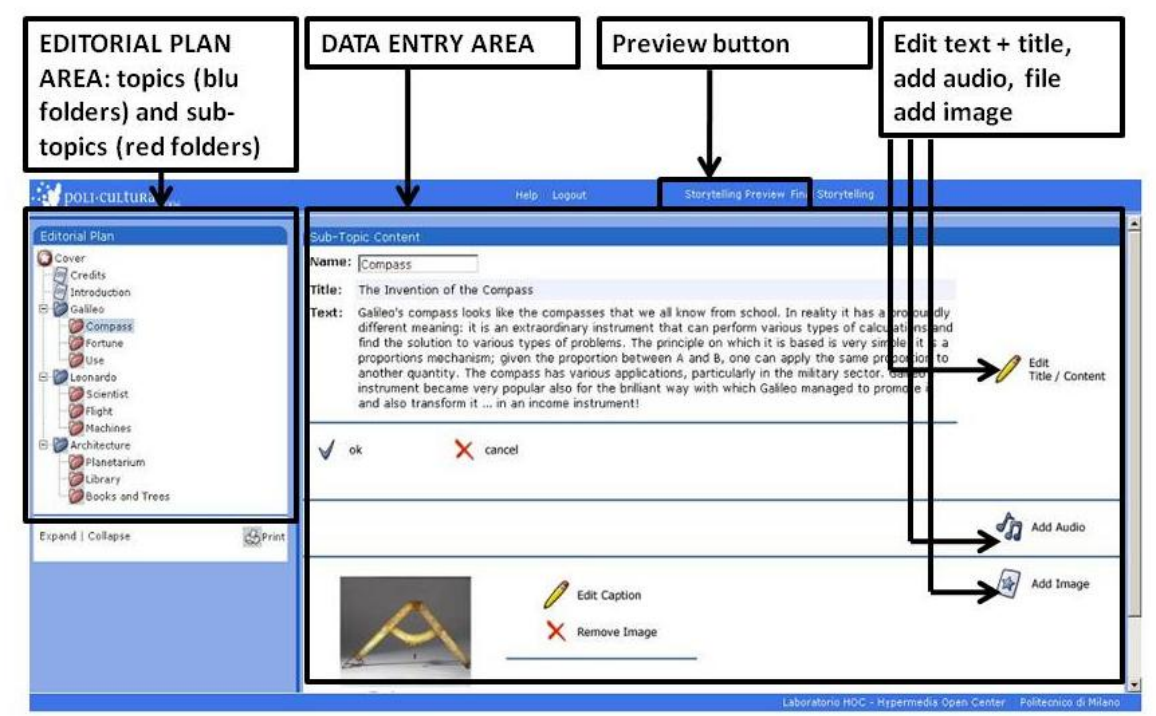

Fig. 3. 1001stories: the authoring interface

The Generation engine takes the data from the CMS and transforms them into playable applications for a number of devices and channels: standard web, downloadable application, application for tablet or smart-phone, etc. Even the delivery on paper is included, in the form of posters and booklets. Images and audio are turned into video files that can be moved around independently (e.g. for hosting them on YouTube).

\subsection{Creating a Narrative}

The narratives can be organized according to two kinds of information architectures: "complete" or "compact". A complete narrative is organized according to a treestructure, with topics and subtopics (Figg. 4 and 5). A compact narrative instead is a linear sequence of topics, without sub-topics. Each content item (topic or subtopic) consists of an audio, a number of images with captions and a text. The optimal length of the audio for each content item is 1 minute approximately (corresponding to a text of 120-200 words), with 6-8 images. 


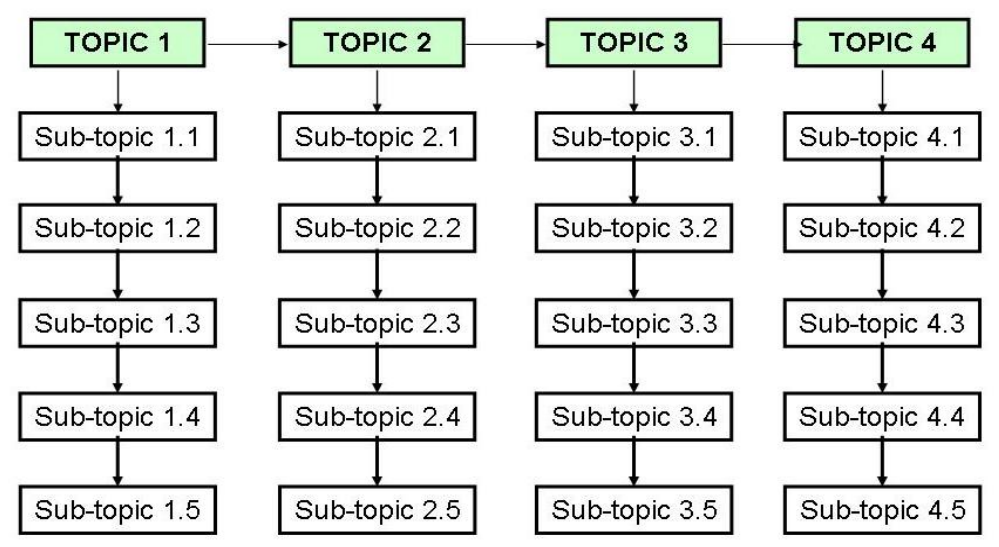

Fig. 4. The information architecture for a "complete" narrative

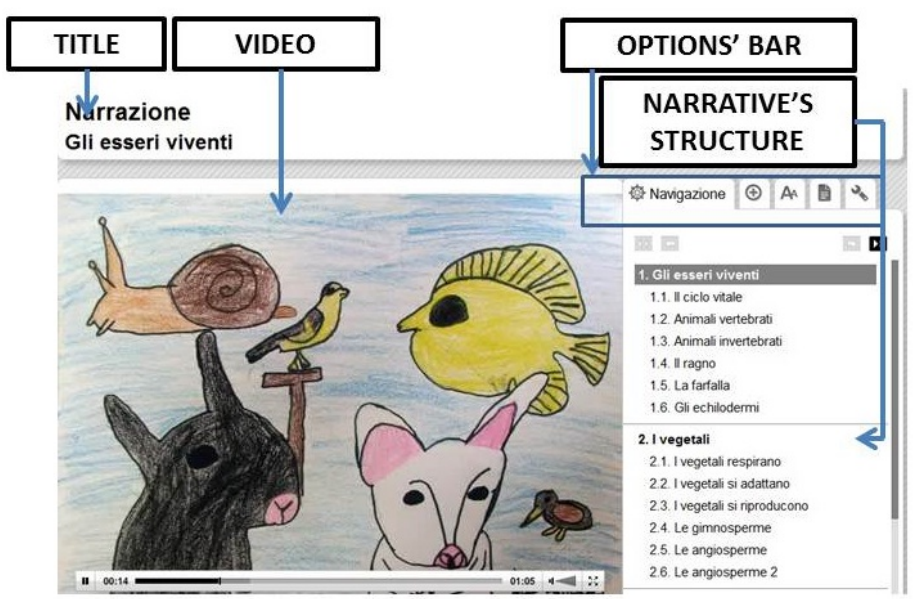

Fig. 5. The web interface of a "complete" narrative

The interaction possibilities vary according to the device/channel being used. For example, touch is used on iPad while playlists are used for MP3 players like iPod. In all cases, two basic patterns are available: the passive one (the application pushes content) and the active one (the user selects what she is interested in).

As the reader can see, the work is channeled by a number of constraints which at first sight may appear as limitations: the information-architecture is rigid, the length of each content item is limited and the direct use of videos is not allowed (the engine generates videos from the images). The reason behind these constraints is this: we wanted to involve as many schools as possible (not only the best ones) and the humanities teachers (the ones that are likely to be the least tech-savvy). 
Thus authoring had to be easy and accessible, and authors had to concentrate on communication rather than on technical issues (like how to edit a video, which is not a trivial task) or design issues (like deciding how to structure content). Six years of experience have shown that these apparent limitations are a trigger for creativity: participants interpret the information architecture in their own way to support various kinds of narrative's structures; kids in primary school create their own drawings which are then scanned and used to generate the videos; the audio component, which we meant as a vocal commentary of the images, in the students' interpretation may become a "music plus voice" commentary, music only, a song by the students, etc.

The suggested production workflow is composed of 5 main steps: (1) theme selection; (2) sketching of the editorial plan; (3) gathering of the material; (4) content's production and refinement; (5) content upload. This basic schema is not always followed: for example, in some cases the topic of the narrative is the object of some other school activity, independent from PoliCultura, therefore a huge amount of material is already there and instead of "gathering the material" the issue is adapting it to the 1001stories format. In other cases, since the class is divided into groups, each group follows its own workflow. As regards the narrative's topics, at first there were two tracks only: local history and local cultural heritage. Now, virtually any subject is allowed, though some special tracks are still suggested, like for example "archeology in your local territory".

\subsection{The "Scent" of the Narratives}

Over the years schools have shown that even with the rather strict constraints described above there is plenty of room for creativity. The multimedia narratives stem from the most various experiences: school outings, social projects, researches, curricular subjects... They are related to almost all the school disciplines, with a preference for humanities. Different multimedia solutions are devised: in many cases music is added to the voice reading the texts as background or in some cases as main communication medium (e.g. a Sicilian boy singing a typical local song). The interested reader can explore our online portal (www.policulturaportal.it), where all the narratives produced so far (700 approximately) are gathered. Let us see now some examples.

The "Stories of the circus" (primary school, 2008) is an example of free interpretation of the "complete" information architecture (Figg. 6 and 7). In the instructions manual, the main topics are described as "summaries of the subtopics", while in the case of the Circus application each topic is not a summary, but a short introduction to a comical story which runs through the sequence of sub-topics (Fig. 7). Thus, the whole application is composed by sequences of short stories. The teacher reported that she had divided the class into groups and each group was in charge of a story. The work was based on a school project in which students had met with circus people. 


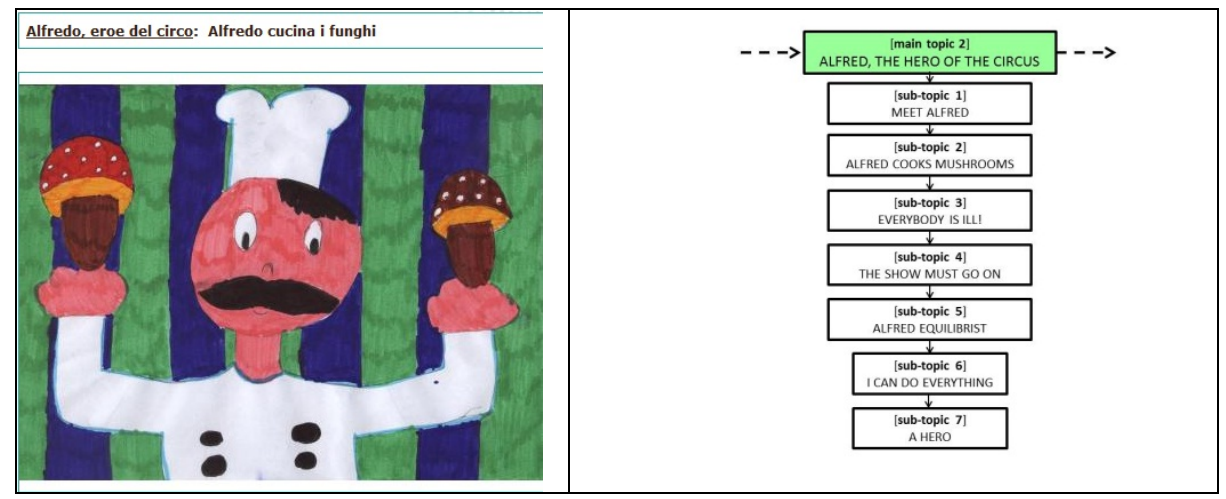

Fig. 6. and 7. The "stories of the circus" (2008, primary school). On the left, Alfred the cook in a drawing by the kids; on the right, the stories' steps: Alfred is the circus cook; he cooks bad mushrooms and everyone falls ill; he plays everyone's parts to save the show and becomes the circus hero.

Especially in the case of narratives by pre-school or primary school students, fiction gets mixed with other literary genres. For example, in the narrative "Pirate Diego and the laws of floating", the sequence of main topics tells the story of the many attempts by the shipwrecked little pirate Diego to build a new ship and the teachings by his parrot (Archimedes) about the laws of floating. In the sub-topics, quizzes are given to the young readers to check whether they are learning too (Fig. 8).

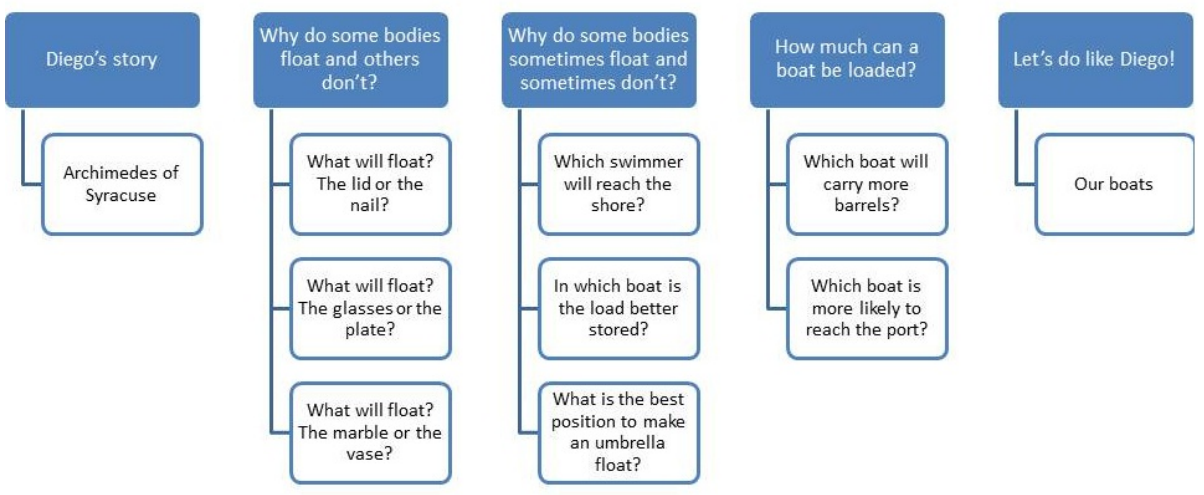

Fig. 8. The information architecture of the narrative "Pirate Diego and the laws of floating"

In the "History of aviation" narrative high-school students decided not to use vocal commentaries but music only as audio. But the music is highly meaningful: for example, when dealing with the Vietnam war, the audio is a powerful music with American soldiers' voices and the sound of helicopters and weapons, which make the narrative's impact quite dramatic (Fig. 9). 

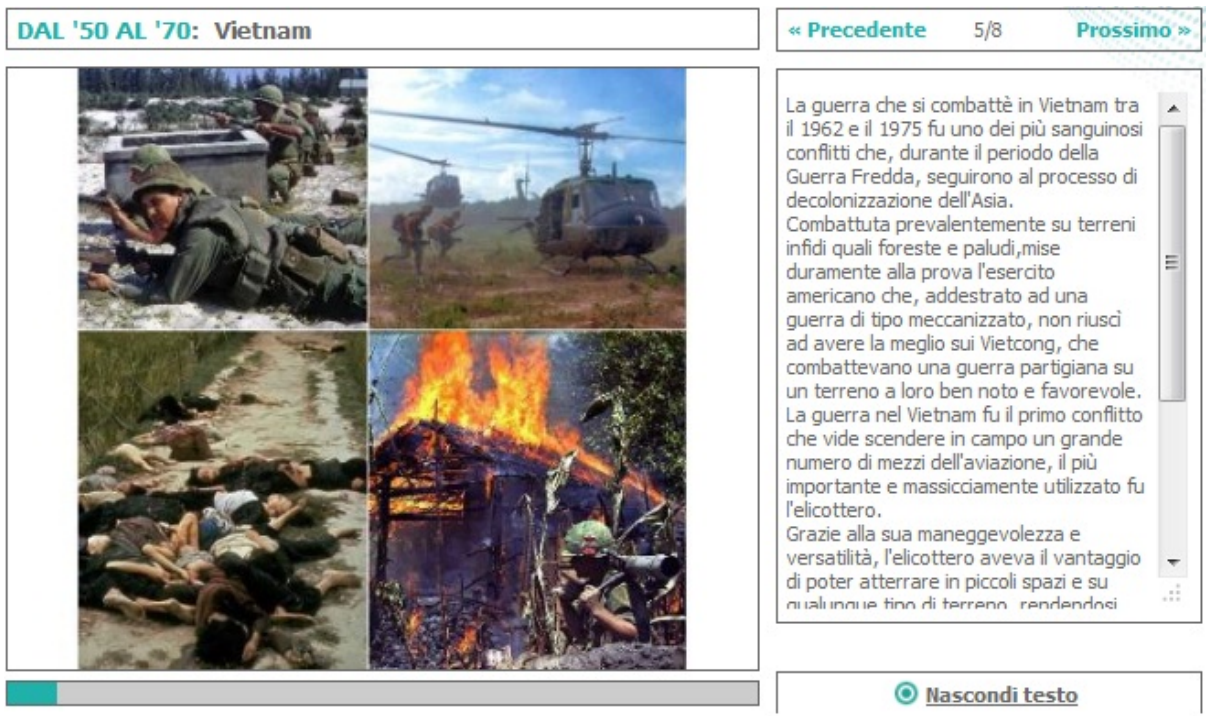

Fig. 9. "History of aviation" (2010, high-school). The audio is music with soldiers' voices, weapons, helicopters; the text, available on demand, tells the story of the Vietnam war.

The narrative called "Padua pocket", by high-school students, capitalizes on the multichannel delivery: it is a multimedia audio guide that takes users around the town of Padua, including the Scrovegni chapel with Giotto's frescos (Fig. 10).

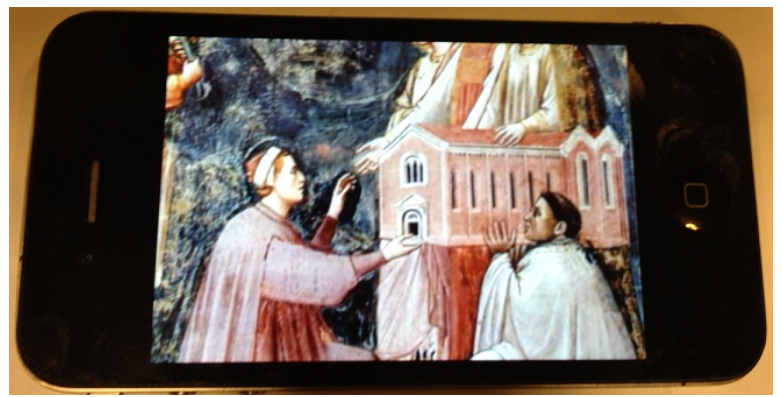

Fig. 10. "Padua pocket" (high-school, 2010), on iPhone

Many narratives deal with the students' local art or history: the narrative that bears the funny title of "A guide for students who are tired of sitting at their desks" tells the story of a school outing to a famous Italian cathedral and its museum. The content is based on a number of interviews with art experts and the museum's curators (Fig. 11).

In some cases students introduced interviews to experts or relevant people in the narratives. That is the case of "I did it just because I'm a man", a narrative by highschool students about Giorgio Perlasca, a man who during the second world war saved thousands of Jews risking his own life. The students interviewed Perlasca's son and skillfully edited the audio to use it in the narrative, again with a quite dramatic effect. 


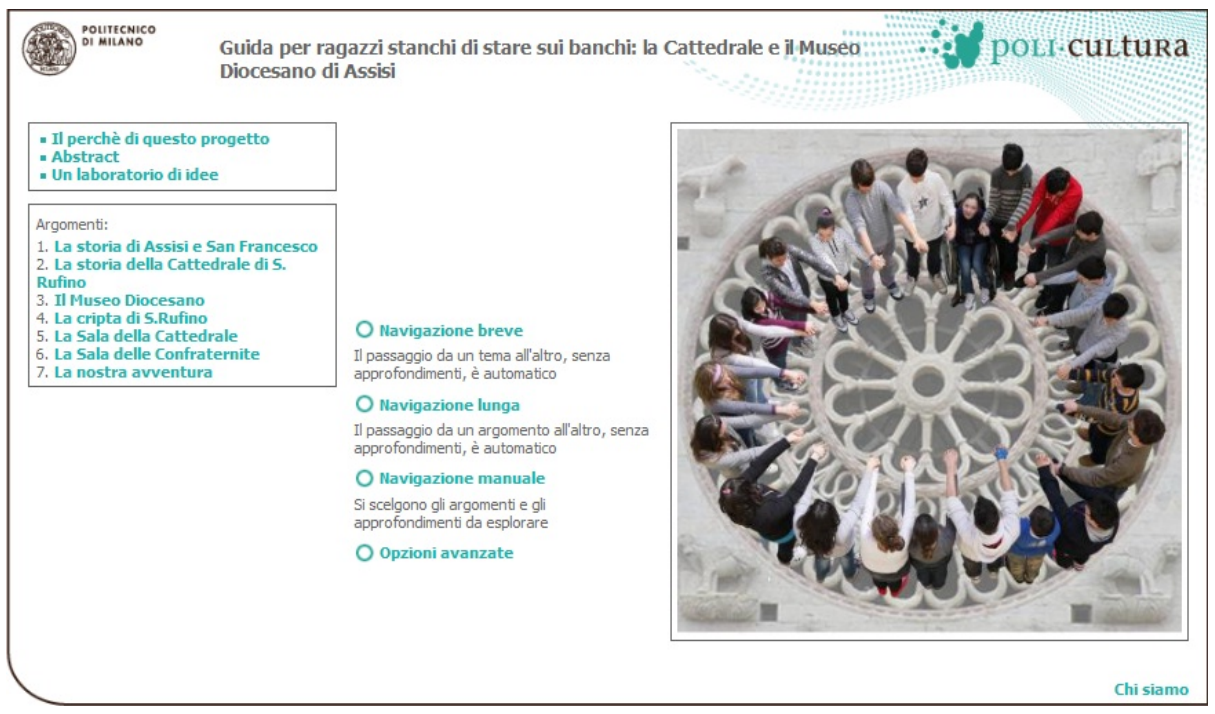

Fig. 11. The front page of a narrative about the Italian cathedral of Assisi (2011, junior highschool); using Photoshop, students placed themselves on the rose window

\section{Evaluation}

Every year, from 2006, the impact of PoliCultura is tested through a number of means: online questionnaires, direct interviews (via skype), focus groups and the analysis of the students' artifacts. Online questionnaires are administered both to the teachers who complete the narrative and take part in the competition and to those who do not complete the narrative and therefore do not take part in the competition. Interviews are taken when the activity is about to start, to investigate the teachers' expectations, and at the end, to investigate the results. Interviews undergo a refinement process which generates a number of documents: the transcript, the "features extraction schema" (in which the main features of the experience are organized), the experience description etc. All these materials are made available through a public online repository, which is being developed in the frame of a national research project (www.learningforall.it).

Focus groups are held each year during the celebration day of PoliCultura: HOCLAB researchers sit together at a round table with 20-30 teachers and school principals. Examples of issues dealt with are: what is the role of technology in education? Would a similar activity - storytelling - work right the same even without the technological support? Do technology-based activities foster inclusion? Do all the students take part in the activity? etc. Eventually, the narratives themselves are object of analysis by a panel of experts.

From 2006 up to now 1400 teachers approximately have filled in 2800 surveys (one before and one after the experience), 100 teachers have been involved in focus groups, 65 teachers have granted in-depth interviews and more than 50 narratives have been 
closely analyzed. In addition, we meet and discuss every year with more than 150 students, when they come for the award ceremony. We do not involve further students in the evaluation for this reason: educational benefits (and not just satisfaction and involvement) are our ultimate goal and their assessment is typically the teachers' job. Therefore we ask teachers to report on their students' improvements. In addition, in other large-scale educational programs (based on MUVEs, with more than 9,000 participants over a period of 5 years), in which surveys were administered to teachers and students, we saw that the surveys' results about benefits always provided comparable results between teachers and students. So, after a while, we stopped double checking, since we found it devoid of any additional information.

\subsection{Benefits}

We briefly present in this section the educational benefits that according to teachers are generated by PoliCultura. Numbers come from the surveys that we administer every year, quotations come from interviews or focus groups. We report the data from the latest edition (2011).

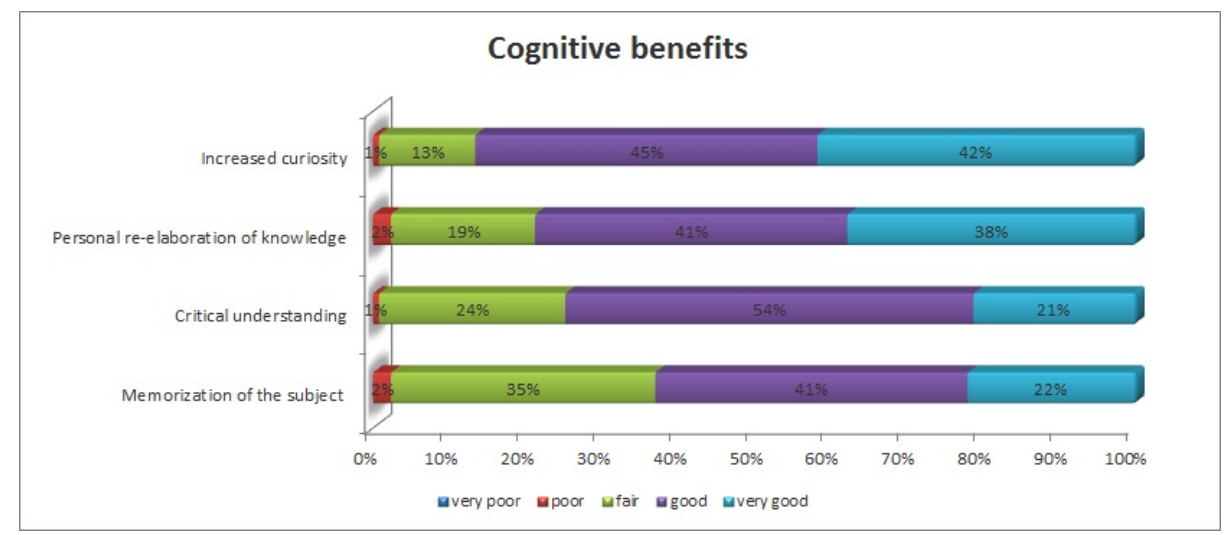

Fig. 12. Students' achievement of cognitive benefits (127 teachers, year 2011)

From the point of view of cognitive benefits (Fig. 12), PoliCultura performs quite well, generating curiosity towards the subject dealt with and favoring the re-elaboration of knowledge (obviously, given the need to build a narrative).

A teacher reports: "The students in my school (a Technical Institute) seem uninterested in learning the techniques of writing, and disaffected about culture in general. The teachers' job gets harder, as we struggle to find strategies for motivating students to express their thoughts in correct forms. The opportunity offered by PoliCultura, that made available to schools such a friendly product of advanced technology to communicate culture, was well accepted: all students in the class could collaborate to create the interactive narrative. Educational results have been excellent, because writing - together with other forms of expression - has become a useful tool, which students use now with increased confidence." 


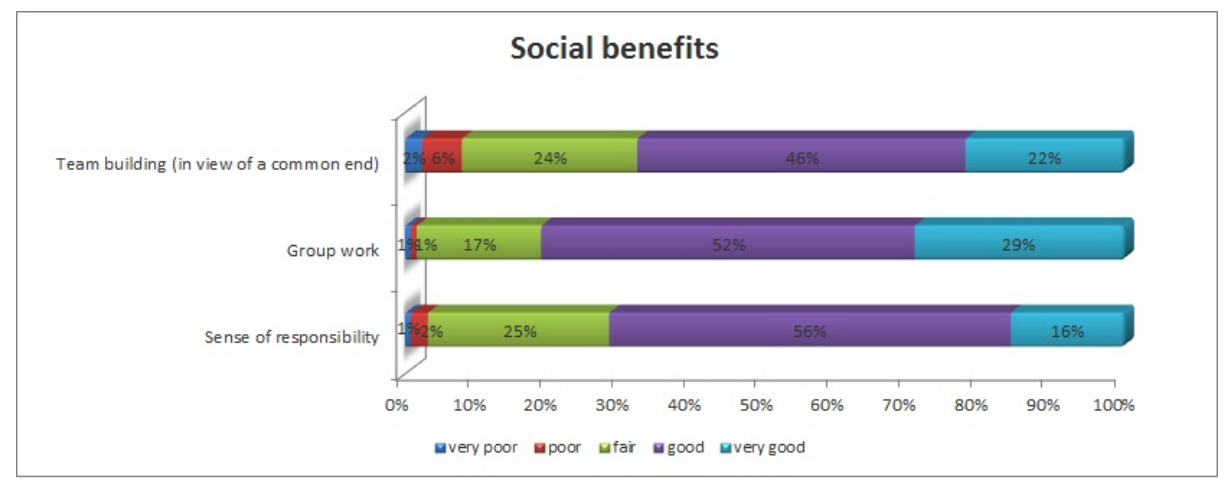

Fig. 13. Students' achievement of social benefits (127 teachers, year 2011)

PoliCultura fosters the development of group-work capabilities: from the interviews we learn from teachers that almost always the whole work is divided into sub-tasks, assigned to small groups of students (2-4 students per group). In addition, the submission deadline and the fact that the work will be made public in the PoliCultura website trigger the students' sense of responsibility and the feeling of cooperating towards a common end: finishing the work on time and hopefully winning the competition.

A teacher reports: "my students are reaching the awareness that group work means coordinating, listening to each other, assigning the tasks etc."

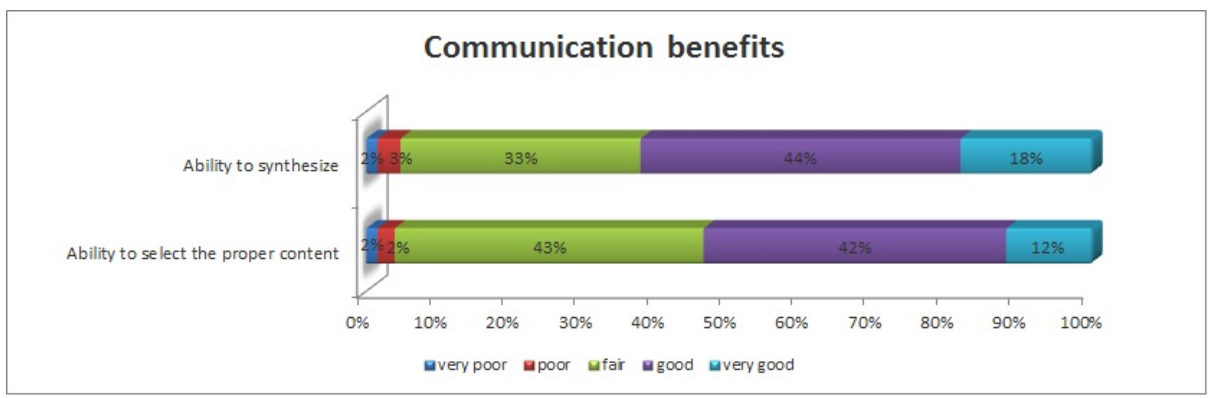

Fig. 14. The students' achievement of communication benefits (127 teachers, year 2011)

The ability to communicate in small content fragments, which is typical of multimedia communication, was in our intention a major benefit, but surprisingly enough teachers hardly mentioned it in the expectations' interviews. Still, when the activity was finished, they did acknowledge it. The reason why teachers tend not to mention communication benefits in the expectations interview is probably the fact that "communication" is not on the official agenda of the curriculum (in Italy).

A teacher reports: "since texts had to be short and 'to the point', students have developed good analysis and synthesis abilities, which in normal school activities are not triggered". 


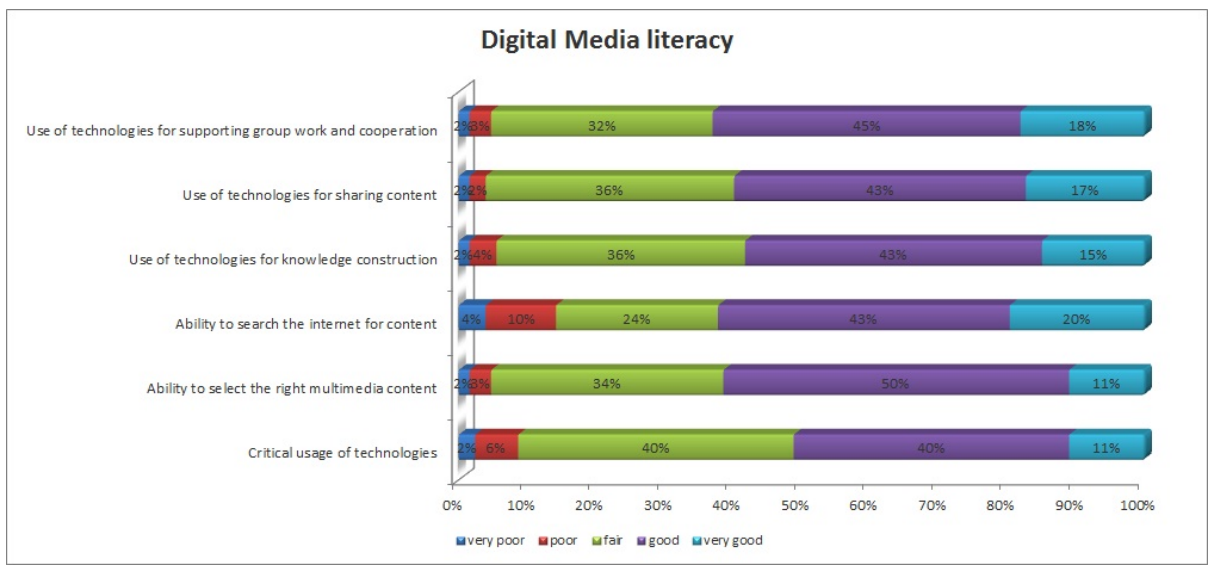

Fig. 15. The students' achievement of digital media literacy (127 teachers, year 2011)

Digital media literacy was an obvious benefit that we expected (Fig. 156). A teacher reports: "the alliance between history and new technologies is highly innovative: it brings students to communicate in a concrete, succinct and visual way; it fosters creativity and the surfacing of personal talents".

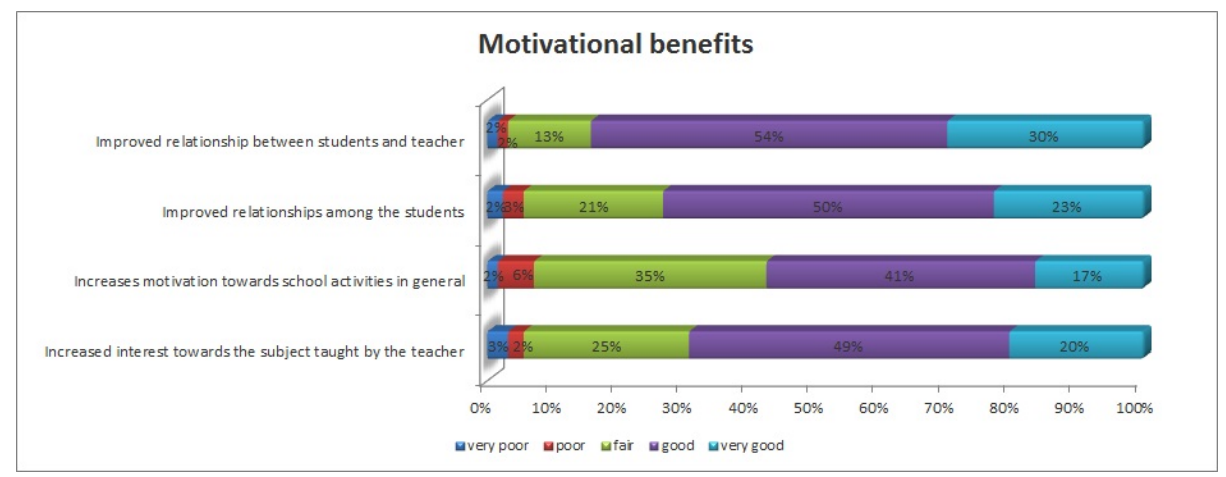

Fig. 16. The students' achievement of motivational benefits (127 teachers, year 2011)

Our experience with technology-based programs is that they can be highly motivating for students and that there is a strong correlation with overall school performances. Teachers report: "PoliCultura has triggered aggregation inside the class; students were so motivated that they worked even beyond school hours"; "PoliCultura generates enthusiasm: students show prolonged attention and they thrive to improve their performances".

\subsection{Inclusion}

ICT can be a powerful means to involve less performing students, especially if they support collaborative activities [18;21]. 


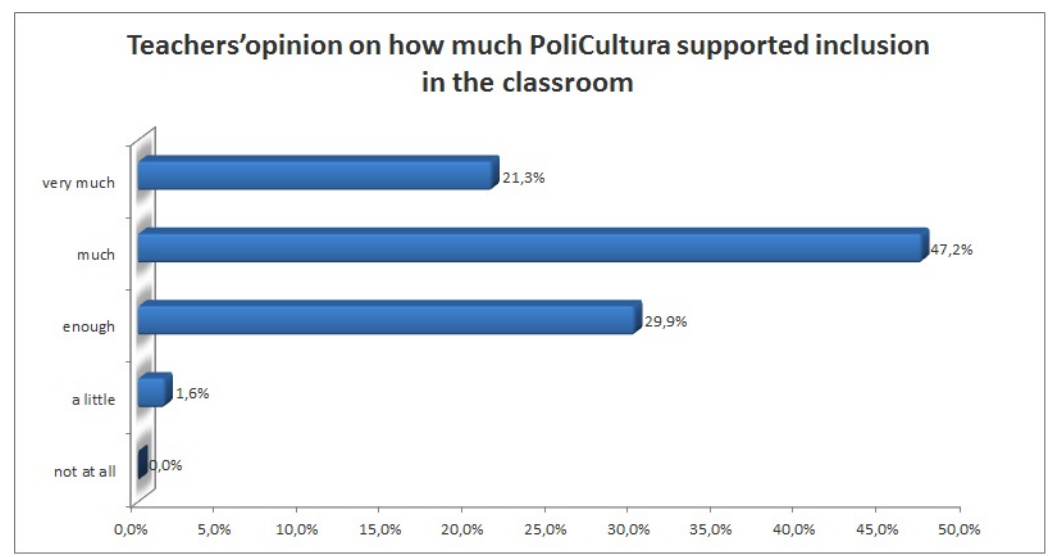

Fig. 17. Inclusion benefits (127 teachers, year 2011)

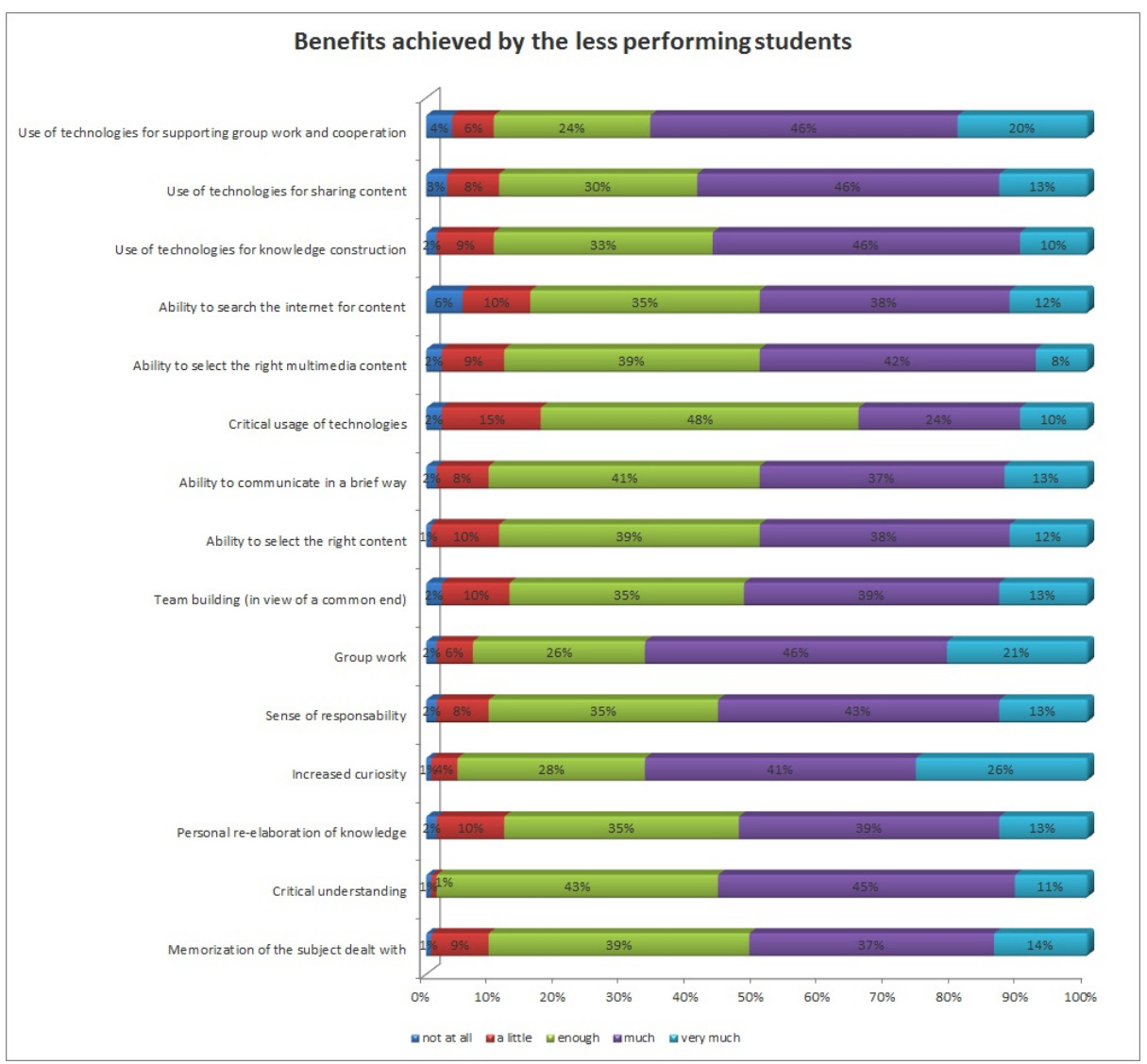

Fig. 18. Inclusion benefits (127 teachers, year 2011) 
In order to double check the overall opinion of the teachers about inclusion, and in order to understand the fine grain of how it worked, we asked more specific questions about the benefits for less performing students (Fig. 18).

Teachers report: "in my class there is a dyslexic kid. He tried to record his part 15, 20 times. He did not want to give up! The whole class stood around him cheering and in the end, he made it"; "PoliCultura has been an occasion to know my students better, especially some kids who proved invaluable in this work, whereas in regular school activity they do not usually stand out".

\subsection{When PoliCultura Does Not Work}

Is PoliCultura the "perfect" experience? Obviously not. Data show that the large majority of the participants who get to the end and create their narrative, even when the result is not fully polished, feel a sense of accomplishment and obtain substantial learning benefits. But every year 50\% approximately of the classes that start do not finish the work. In year 2010-2011, for example, 325 classes registered. 173 classes $(53.2 \%)$ completed the narrative, 149 of which on time for the competition, and 25 later, but still before the end of the school year. When and why did 152 classes $(46.8 \%)$ stop working at PoliCultura?

More that $56 \%$ of the classes that stop their work do this very early, somehow realizing that the enterprise is too demanding (Fig. 19). The question is: what happens to those classes that drop out when $50 \%$ (or more) of the work is already done? Why do they fail?

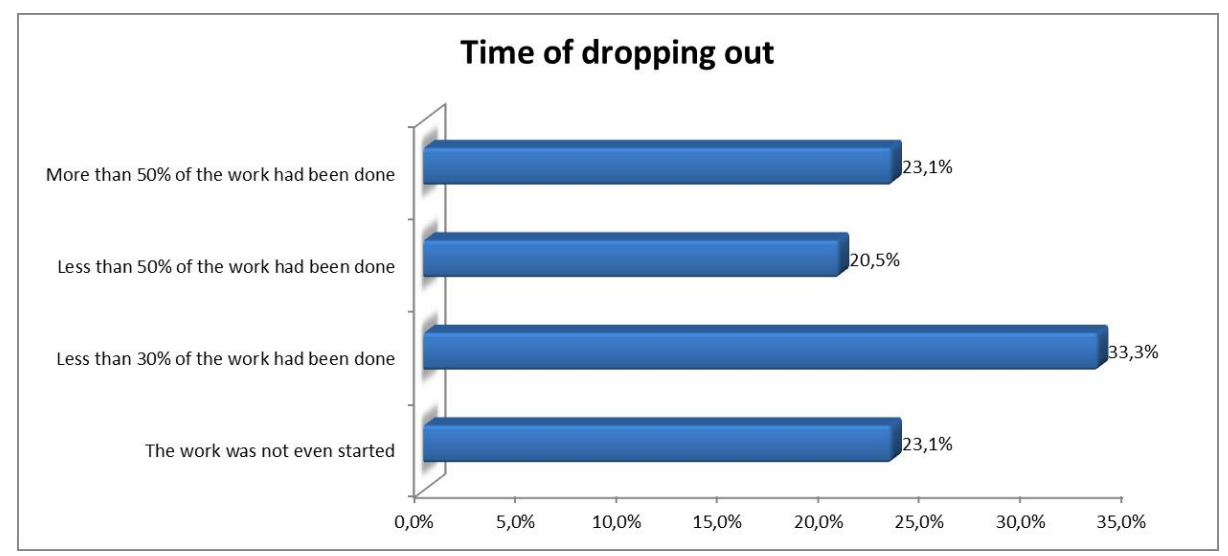

Fig. 19. When classes stop working at PoliCultura

Most of the motivations for dropping out are related to the "context" in a broad sense (time, resources, lack of support by the principle and the school council, etc.) but not to the idea of building a multimedia narrative. In other words, participants do not drop out because they think that creating a multimedia narrative is not worthwhile but for other practical or contextual reasons (Fig. 20). 


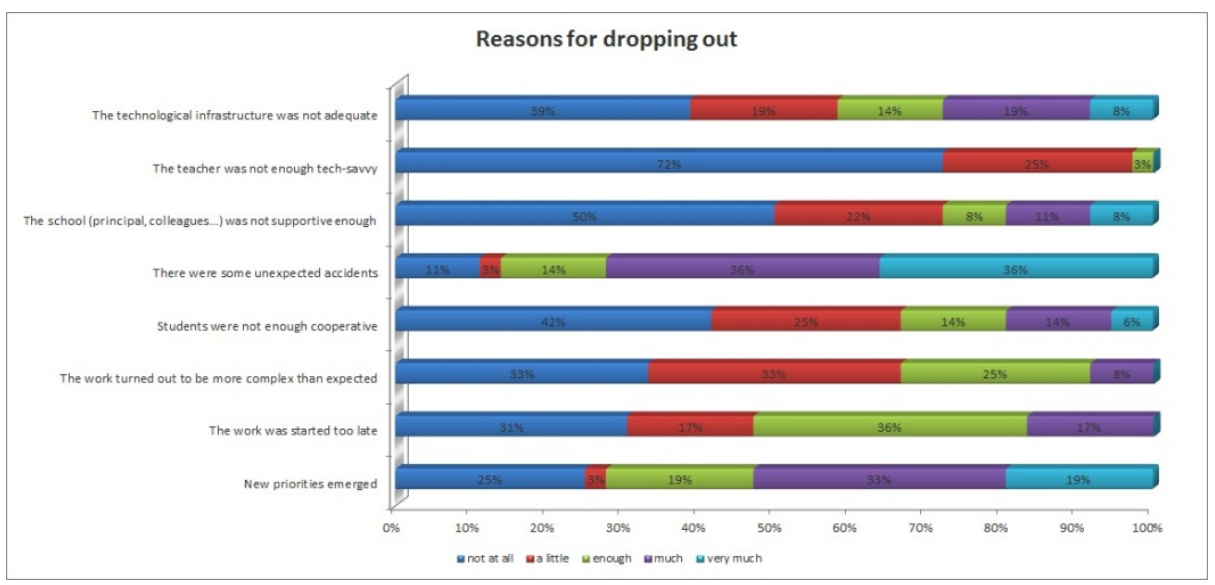

Fig. 20. Why classes stop working at PoliCultura

\section{$4 \quad$ Related Works}

Digital storytelling is quite a huge field; due to the focus of this paper, in this section we will introduce systems that are meant for educational use and more specifically for authoring multimedia digital stories rather than for supporting passive consumption [19]. We must warn the reader that none of these systems was a source of inspiration for PoliCultura and 1001stories, which, as explained above, was created to support professional authoring of multimedia content in the field of cultural heritage and was then transferred as it was into school environments for educational use.

Authoring tools for digital storytelling have been mainly developed for young children, being the educational value of authoring a story strongly backed by those pedagogical theories that consider learning as knowledge building rather than knowledge transmission [15]. A number of tools have been developed to support this activity, both in the academic and commercial arena. Still, commercial products tend to see users more as listeners than authors; if they are considered as authors, then they are generally provided with readymade characters with which they can play rolegames at most. These products are often CD-rom based, they impose strong limitations to creativity and almost never allow cooperation or sharing of the stories with other peers [2]. Academic prototypes and projects afford more creativity [7; 17; 25]. Many approaches make use of physical elements to trigger the process of storymaking. For example, MIT's StoryMat records and recalls children's voices as they play with stuffed animals on a colorful, story-evoking, quilt [6]. Other approaches, like SAGE [4] and PET [14], integrate tangible elements (like stuffed animals) into the technology-enhanced storytelling process. StoryRoom also adopts a physical approach by providing kids with room-sized interactive storytelling spaces where they share a theatrical experience [1]. ShadowStory, eventually, is a digital storytelling system inspired by traditional Chinese shadow puppetry. Using a Tablet PC children at primary school level create digital characters and perform live stories together on a 
projection screen [22]. Other approaches provide children with online tools for supporting the story creation process. A recent development is G-Flash, an authoring tool for primary school children that supports that story creation using illustrated flashcards, with characters and scenarios [20]. Wayang is another online authoring platform, developed by the dimeb Research Group of Bremen University, meant to allow students to express their cultural diversity. Children create either individual or collaborative stories by using digital puppets [29].

Other approaches make use of virtual environments in which the stories take place, like PUPPET, an autonomous agents-populated virtual environment where children play multiple roles in creating narratives [23]. Collaborative storytelling has also been explored, but mostly at experimental level. MOOSE crossing, for example, allows kids to cooperatively design and build objects and virtual characters in a virtual space [5]. The FaTe project allows very young kids (aged 5 to 8 ) to develop stories together in a shared 3D environment [16]. ToonTastic is a tool, still in its beta phase, meant to enable children to collaboratively create a story using an interactive, multiple-pen display [28]. Eventually, CBC (Canadian Broadcasting Corporation) 4Kids's StoryBuilder is one of the rare examples of large-scale exploitation of a digital storytelling system. Children can create multimedia comix-style stories, based on the typical mechanism of "add-a-sentence-to-a-story". They can then save their stories in an online personal space and also publish them and share them with friends, via email [2]. Digital drawing, especially if collaborative, has also been considered a form of storytelling, like in the KidPad project [3].

What differentiates 1001stories with respect to the above systems? First of all, 1001stories addresses a wider audience of users, aged between 4 to 18 (and even more, if professional usage is considered). In addition, it must be noted that the tool does not undergo any form of adaptation to fit the various age-ranges. Second, no ready-made element that could influence the story-creation process is introduced, like stuffed animals, virtual character, themes or story-patterns. Third, when used in formal education it supports (like some of the above systems do) collaborative storytelling, with an educational aim. Fourth, the simplicity of the authoring process goes with a sophisticated multi-channel delivery (web for PC, smartphone, playlist for MP3 players, multi-touch tables etc.). 1001stories approach could be summarized with a metaphor by the famous architect Mario Botta, who used to say that even without a full palette of colors, but with just a black and white pencil, it is possible to make beautiful drawings. 1001stories is almost trivial in its simplicity, but it allows drawing beautiful things.

\section{Conclusions}

Six years of deployment of PoliCultura with more than 17,000 participating students demonstrates that digital storytelling can be successfully introduced in school environment and produce educational benefits. In our opinion, the reasons why this initiative works well are: 
- $\quad$ the authoring environment is easy to use, so that non tech-savvy teachers can join the activity;

- the final result is highly innovative for school standards (multimedia, multidevice, interactive, ...) and thus it is perceived as "cool" by the students. All the interviewed teachers say that without the perspective of a multimedia narrative the class would not have worked in the same way. A comparative study, comparing traditional storytelling with 1001stories, confirms the crucial role of technology [27];

- hints on the workflow are provided in the instruction manual, but the pedagogical implementation of the activity is $90 \%$ in the hands of the teacher and the pupils;

- the storytelling activity is not isolated but strictly related to the curriculum and the educational goals.

- visibility of the final work, in a public website, is a strong "kick". It was spontaneously mentioned by $75 \%$ of the interviewed teachers as one of the main motivating factors for the students.

- the competition also acts as a powerful motivation factor. Being goal directed is one of the many characteristic that in Csikszentmihalyi's option an activity should have in order to foster a sense of flow (i.e. deep involvement) in the participants $[8 ; 10]$.

- PoliCultura is a collaborative activity to which classes take part as a whole. Thus students learn that their individual efforts and talent are a resource for the group and they learn how to deal with group work issues;

- last but not least, the narrative creation based on technology triggers a reshuffling of roles and the surfacing of new talents. This change, if well coordinated by the teacher, generates inclusion, in the sense that even less performing students get more motivated and get a feeling of accomplishment, thanks to the fact that they are part of the team;

Our main research direction now is to further investigate through detailed interviews to teachers the educational benefits and the way they are related to the pedagogical implementation. As far as authoring is concerned, our future steps are:

- expanding the narrative formats, especially improving the versions for mobiles and tablets;

- adding new features to our authoring environment specifically meant to support the final phases of the narrative's creation, to allow authors to check and make changes in a quick and efficient way;

- $\quad$ integrating the authoring environment with a LMS (Learning Management System) in order to support all the phases of the narrative creation, including the collection of the material, the groups' organization, the discussion, etc.

Finally our new international portal (www.policulturaportal.it) is the occasion for providing more national visibility and, more important, to start making PoliCultura an international adventure. 
Acknowledgments. We warmly thank the HOC-LAB staff who passionately work for making PoliCultura a success every year, especially Elena Maccari, PoliCultura's project manager.

This work is partially supported by National Project L4A ("Learning for All") Grant Num RBNE07CPX 001.

\section{References}

1. Alborzi, H., Druin, A., Montemayor, J., Platner, M., Porteous, J., Sherman, L., Boltman, A., Taxén, G., Best, J., Hammer, J., Kruskal, A., Lal, A., Schwenn, T.P., Sumida, L., Wagner, R., Hendler, J.: Designing StoryRooms: Interactive Storytelling Spaces for Children. In: Proceedings of Symposium on Designing Interactive Systems, pp. 95-104 (2000)

2. Antle, A.: Case study: the design of CBC4Kids' StoryBuilder. In: MacFarlane, S., Nicol, T., Read, J., Snape, L. (eds.) Proceedings of IDC 2003, IDC 2003, Preston, England, July 01-03, pp. 59-68. ACM, New York (2003)

3. Benford, S., Bederson, B.B., Akesson, K., Bayon, V., Druin, A., Hansson, P., Hourcade, J.P., Ingram, R., Neale, H., O’Malley, C., Simsarian, K., Stanton, D., Sundblad, Y., Taxén, G.: Designing Storytelling Technologies to Encourage Collaboration Between Young Children. In: Proceedings of CHI 2000, pp. 556-563. ACM, New York (2000)

4. Bers, M., Cassell, J.: Interactive storytelling systems for children: using technology to explore language and identity. Journal of Interactive Learning Research 9, 183-215 (1998)

5. Bruckman, A.: MOOSE Crossing: Construction, Community and Learning in a Networked Virtual World for Kids. Unpublished thesis. MIT, Cambridge (1997)

6. Cassell, J., Ryokai, K.: Making Space for Voice: Technologies to Support Children's Fantasy and Storytelling. Personal Ubiquitous Computing 5(3), 169-190 (2001)

7. Cassell, J. (ed.): Proceedings of IDC 2008, Chicago, USA, June 11-13. ACM, New York (2008)

8. Csikszentmihalyi, M.: Flow: The Psychology of Optimal Experience. Harper \& Row, New York (1990)

9. Di Blas, N., Garzotto, F., Paolini, P., Sabiescu, A.: Digital Storytelling as a Whole-Class Learning Activity: Lessons from a Three-Years Project. In: Iurgel, I.A., Zagalo, N., Petta, P. (eds.) ICIDS 2009. LNCS, vol. 5915, pp. 14-25. Springer, Heidelberg (2009)

10. Di Blas, N., Garzotto, F., Poggi, C.: Web Engineering at the frontiers of the Web 2.0: Design Patterns for online 3D Multiuser Spaces. World Wide Web Journal 12(4), 345-379 (2009), doi:10.1007/s11280-009-0065-5

11. Di Blas, N., Paolini, P., Rubegni, E.: How to Build Multi-Media and Multi-Channel Corporate Brochures. In: Proceedings of the IEEE Professional Communication Conference, July 7-9. University of Twente, The Netherlands (2010)

12. Di Blas, N., Paolini, P., Sabiescu, A.: Collective Digital Storytelling at School as a WholeClass Interaction. In: Proc. IDC 2010. ACM, New York (2010)

13. Di Blas, N., Paolini, P., Torrebruno, A.: Digital Storytelling at School: Does the TPCK Model Explain What's Going On? In: E-Learn 2010 Conference, Orlando, Florida, October 18-22 (2010)

14. Druin, A., Montemayor, J., Hendler, McAlister, B., Boltman, A., Fiterman, E., Plaisant, A., Kruskal, A., Olsen, H., Revett, I., Plaisant- Schwenn, T., Sumida, L., Wagner, R.: Designing PETS: A Personal Electronic Teller of Stories. In: Proceedings of CHI 1999. ACM Press (1999) 
15. Feher, P.: Towards effective student-centered, constructivist learning: Build Your Own Digital Story! In: ED-MEDIA 2008, pp. 2364-2367. AACE, Chesapeake (2008)

16. Garzotto, F., Forfori, M.: FaTe2: storytelling edutainment experiences in 2D and 3D collaborative spaces. In: Proceedings of IDC 2006, pp. 113-116. ACM, New York (2006)

17. Göttel, T.: Reviewing Children's Collaboration Practices in Storytelling Environments. In: Proceedings of the 10th International Conference on Interaction Design and Children, pp. 153-156. ACM, New York (2011)

18. Hooper, S., Hannafin, M.: The effects of group composition on achievement, interaction, and learning efficiency during computer-based cooperative instruction. Educational Technology Research and Development 39(3) (1991)

19. Iurgel, I.A., Zagalo, N., Petta, P. (eds.): ICIDS 2009. LNCS, vol. 5915. Springer, Heidelberg (2009)

20. Jumail Rambli, D.R.A., Sulaiman, S.: G-Flash: An authoring tool for guided digital storytelling. In: IEEE Symposium on Computers \& Informatics, ISCI, pp. 396-401 (2011), http: / / ieeexplore. ieee. org/stamp/stamp. j.sp? tp=\&arnumber $=5958$ 948\&isnumber $=5958864$ (retrieved January 9, 2012)

21. Lou, Y., Abrami, C.A., Spence, J.C., Poulsen, C., Chambers, B., d'Apollonia, S.: Withinclass grouping: A meta-analysis. Review of Educational Research 66 (1996)

22. Lu, F., Tian, F., Jiang, Y., Cao, X., Luo, W., Li, G., Zhang, X., Dai, G., Wang, H.: ShadowStory: creative and collaborative digital storytelling inspired by cultural heritage. In: Proceedings of the 2011 Annual Conference on Human Factors in Computing Systems, pp. 1919-1928. ACM, New York (2011),

http: / / doi.acm.org/10.1145/1978942.1979221 (retrieved January 9, 2012)

23. Marshall, P., Rogers, Y., Scaife, M.: The value of a virtual environment for learning about narrative. SIGGROUP Bull 23(2), 14-15 (2002),

http: / / doi.acm.org/10.1145/962185.962190 (retrieved January 9, 2012)

24. Mishra, P., Koehler, J.M.: Technological Pedagogical Content Knowledge: A Framework for Teacher Knowledge. Teachers College Record 108(6), 1017-1054 (2006)

25. Paolini, P., Garzotto, F. (eds.): Proceedings of IDC 2009, Como, Italy, June 3-5. ACM, New York (2009) (entire issue)

26. Rubegni, E., Di Blas, N., Paolini, P., Sabiescu, A.: A Format to design Narrative Multimedia Applications for Cultural Heritage Communication. In: Proceedings of SAC 2010, Sierre, Switzerland, March 22-26 (2010)

27. Rubegni, E., Paolini, P.: Comparing canonical and digital-based narrative activities in a formal educational setting. In: Proceedings of the 9th International Conference on Interaction Design and Children, IDC 2010, Barcelona, Spain, June 9-11 (2010)

28. Russell, A.: ToonTastic: A Global Storytelling Network for Kids, by Kids. In: Conference on Tangible, Embedded and Embodied Interaction, TEI 2010, Cambridge, MA, USA, January 25-27 (2010)

29. Widjajanto, W.A., Lund, M., Schelhowe, H.: "Wayang Authoring": a web-based authoring tool for visual storytelling for children. In: Kotsis, G., Taniar, D., Pardede, E., Khalil, I. (eds.) Proceedings of the 6th International Conference on Advances in Mobile Computing and Multimedia, pp. 464-467. ACM, New York (2008),

http: / / doi.acm.org/10.1145/1497185.1497284 (retrieved January 9, 2012) 